\title{
The Use of Medication by the Spanish Population
}

\author{
M. CARMEN DEL RIO MD, CARLOS PRADA MD AND F. JAVIER ALVAREZ MD \\ Department of Pharmacology and Therapeutics, Faculty of Medicine, University of Valladolid, Valladolid, Spain
}

\begin{abstract}
SUMMARY
The aim of the study was to assess patterns of the use of medicines by the general population older than 0 years. The study was based on the information contained in the computerized database from the 1993 Spanish Household Health Survey. A representative sample of the population older than 0 was identified, and a survey of 26,334 persons was carried out. Of the population $45.3 \%$ had taken some medicine in the last 2 weeks prior to the carrying out of the survey. The proportion was greater for women $(50.6 \%)$ than for men $(39.6 \%)$. With increasing age, the frequency and amount of medication use increased. A little over $20 \%$ of the medicines used were not prescribed by a doctor (self-medication). Data show the frequency of the use of medicines by the Spanish population. (C) 1997 by John Wiley \& Sons, Ltd.
\end{abstract}

Pharmacoepidemiology and Drug Safety 6: 41-48, 1997

No. of Figures: 2 No. of Tables: 3 No. of Refs: 22

KEY WORDS - drug utilization trends; self-medication; age factors; sex factors; adult; child; general population

\section{INTRODUCTION}

The vast number of commercialized drugs, the great amount of medication used, and the rationality of such use have become major concerns for the public health authorities in many industrialized countries in the last few years. ${ }^{1-3}$ Related to medication use, qualitative aspects are as important as quantitative ones: how are these medicines used? What positive or negative effects do they have on health in the community? etc.

Qualitative drug utilization studies provide useful information allowing us to develop strategies leading to a more rational use of medications. However, the majority of published drug utilization studies are based on information derived from sales and prescriptions; ${ }^{1-3}$ drug utilization studies based on a consumer approach are rare, despite the

Addressee for correspondence: F. Javier Alvarez, Department of Pharmacology and Therapeutics, Faculty of Medicine, University of Valladolid, 47005 Valladolid, Spain, fax: + (34 83) 423073 and + (34 83) 423022 .

CCC 1053-8569/97/010041-08\$17.50

(C) 1997 by John Wiley \& Sons, Ltd. great amount of information they provide. The need for standard methodology in drug utilization studies has already been acknowledged. ${ }^{4}$ In recent years, it has been pointed out that a complete assessment of drug use should also take the social aspects into account. ${ }^{5}$

Consequently, the aim of this study has been the characterization of the use of medicines among the population from zero years of age onwards, the basis being the 1993 Spanish Household Health Survey.

Spain has a population of about 38 million, and the National Health Service covers nearly all of the population. ${ }^{6}$ Since the 1970s, the Drug Regulatory Authority has reviewed Spanish pharmaceutical products, thus ensuring the efficacy, safety and quality of the available medicines as a first step towards the rational use of drugs. One of the activities developed was the 'Prosereme programme', through which all pharmaceutical products were reviewed and many medicines were withdrawn or their formulations altered. ${ }^{6}$ A study carried out in $1981^{7}$ showed that $41 \%$ of the 
medication used in that year was of high potential value; $12 \%$ of relative value; $25.5 \%$ of doubtful or no value, and $21.4 \%$ was rated as unacceptable. Fortunately, in our opinion, the present situation has largely changed.

In the last few years special efforts have been made to reduce medication costs to the National Health Service, as well as promoting rational medication use. ${ }^{8}$ The latest figures show that medication costs have increased year by year, from 178,348 in 1984 to 641,701 in 1994 (figures in million pesetas, 125 pesetas about 1 US dollar). The number of prescriptions increased between 1984 (432 million prescriptions) and 1992 (519), and then decreased in 1993 (506) and 1994 (494). Several databases, basically related to the prescribed drugs throughout the National Health Service and their cost, are currently available in our country. ${ }^{6}$ These have been used in the performance of drug utilization studies. However, assessment of the social aspects of medication use by Spaniards has not undergone the same amount of research.

\section{METHODS}

The study was based on information contained in the computerized database of the Spanish Household Health Survey carried out by the Spanish Ministry of Health in 1993. ${ }^{9}$ The work was under the auspices of the Subdirección General de Información Sanitaria y Estadísticas Sanitarias. The field work and recording of the information was carried out by the Centro de Investigaciones Sociológicas. The aim of the survey was to obtain information concerning the aspects related to health and the use of health resources, including the use of medications.

A survey of 26,334 people $(21,084$ adults and 5,250 children under 16 years of age) who were a representative sample of the non-institutionalized Spanish population older than 0 years, was carried out. The sample was designed to be representative both at national and Autonomous Community (Regional) level. The sampling error, with a confidence level of $95.5 \%$, was $0.8 \%, 0.9 \%$ in the case of adults and $1.8 \%$ in the case of children.

A complex multistage sample design was used. It was designed as follows: first, by the Spanish communities (there are 17 Autonomous Communities plus Ceuta and Melilla, comprising a total of 52 provinces); second, by seven stages according to the number of inhabitants: $<2000$ $(n=2249), 2001-10,000(n=4510), 10,001-50,000$ $(n=6110), 50,001-100,000 \quad(n=2231), 100,001-$ 400,000 $(n=6160), 400,001-1,000,000(n=1715)$ and $>1,000,000(n=3329)$, (missing $n=29)$; third, by cities in each one of the communities, and finally, by age group: $1-10$ years $(n=3350), 11-20$ $(n=4176), 21-30 \quad(n=4228), 31-40 \quad(n=3564)$, $41-50 \quad(n=3147), \quad 51-60 \quad(n=2971), \quad 61-70$ $(n=2805),>70 \quad(n=1745) \quad($ missing $n=348)$, and by gender (males, $n=12,862$; females, $n=13,416$; missing $n=56$ ).

Questionnaires were completed by direct interview with selected people. The questionnaires were administered by trained interviewers. Regarding the children, the questionnaire was answered by their father, mother or guardian. When a person selected was unavailable or unwilling to be interviewed a replacement was chosen.

Although the questionnaires were different in both age groups (adults and children), they both included items relating to medication use. Those surveyed were asked: (i) if they had taken any kind of medicine in the last 2 weeks, (ii) if so, what kind of medicine they had taken (using 17 different therapeutics categories among adults, and 11 in the case of children), (iii) for each type of medication, if the medicine used was prescribed by a doctor or not (the latter case, was considered as self-medication).

Analysis of the data was carried out in the Data Processing Centre at Valladolid University, using the statistical package SAS (Version 6.07). $p$ Values $\leqslant 0.05$ were considered to show significant differences.

\section{RESULTS}

Of the Spanish population $45.3 \%$ had used some kind of medication in the two previous weeks (Fig. 1), 39.6\% were men and 50.6\% women $\left.\chi_{1}^{2}=314.10, p<0.0001\right)$. These differences also exist in the adult group $(40.5 \%$ of men and $53.2 \%$ of women, $\left.\chi_{1}^{2}=332.71, p<0.0001\right)$, but not in the children's age group $(<16$ years of age): $36.4 \%$ for boys and $39.8 \%$ for girls $\chi_{1}^{2}=6.25$, $p>0.05)$. From the $11-20$ age group, the frequency of medicines used increased with age (Fig. 1). This trend was observed in both men and women.

The average number of medicines used (Fig. 2), increased in the 11-20 years age group, the increase being greater for women $(1.50 \pm 0.65$, mean \pm SD) than for men $(1.38 \pm 0.72 ; F=8 \overline{5} .02, p<0.0001)$. If we analyse the number of medicines used (one, two, 


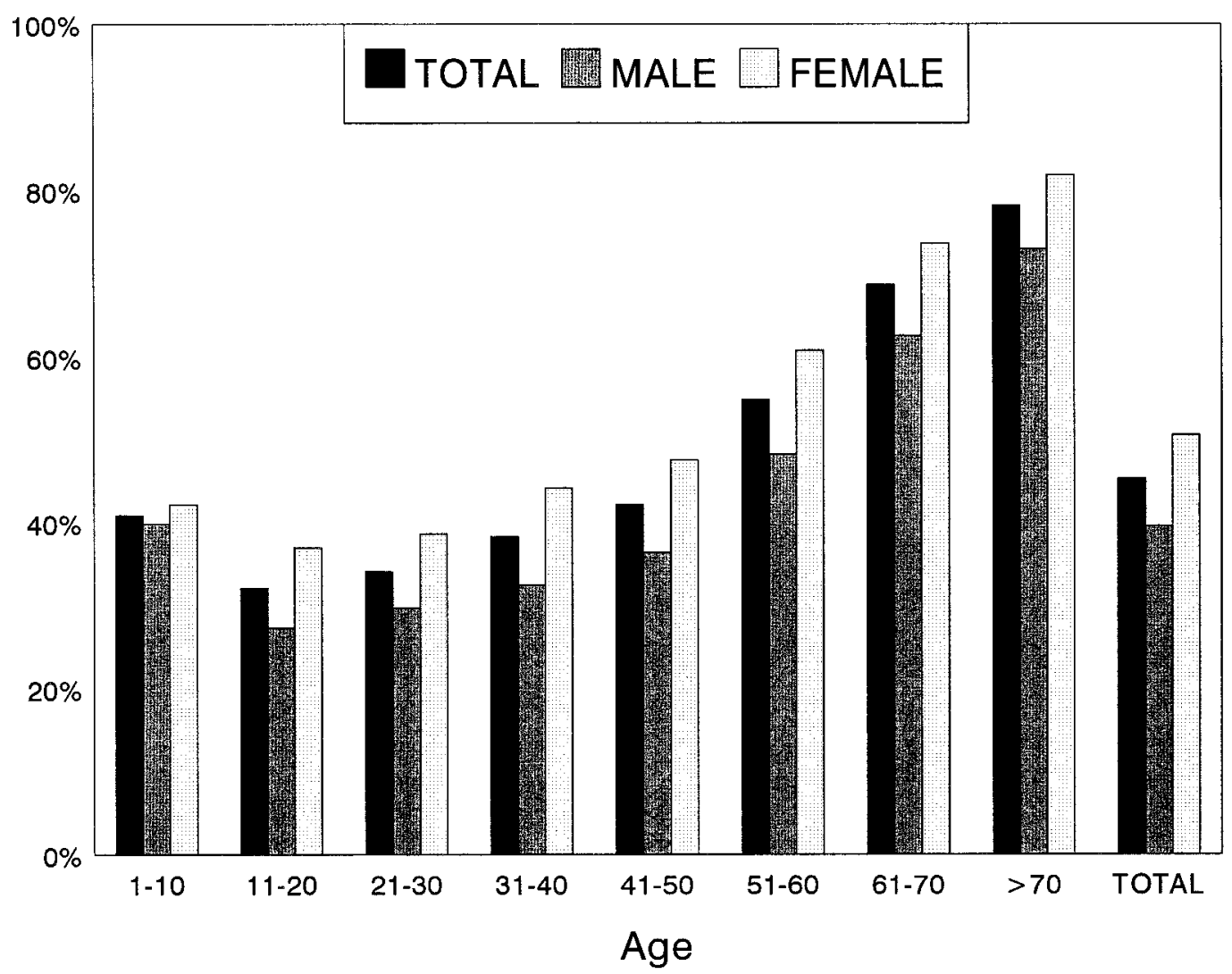

Fig. 1 - Medication use by the population

three or more) per age group (Fig. 2), it is clear that, from the 11-20 age group, the taking of only one medicine decreased with age, with the taking of two, three or more medicines increasing in a parallel way. With regard to sex, differences were observed $\left(\chi_{2}^{2}=84.59, p<0.0001\right)$ : men take only one medicine $(71.4 \%)$ more frequently than women $(63.8 \%)$, while women take two $(22.6 \%)$, three or more $(13.7 \%)$ medicines at a greater rate percentage-wise than men $(19.4 \%$ and $9.2 \%)$.

There were differences in medicine used among adults depending on certain sociodemographic variables (Table 1): medicine use was more frequent the greater the size of the population; use was also more frequent among those who were widows, people with no schooling and the retired. These trends are found among both sexes.

In the adult population surveyed (Table 2), the most frequent groups of drugs taken were respiratory products $(14.9 \%)$, analgesics/antipyretics $(10.8 \%)$ and hypotensives $(7.8 \%)$. In most groups, the use of medicine was more common among women. Gastrointestinal preparations were more frequently used by men. No differences existed between the sexes in respect of respiratory products, cardiac therapy, and antiallergic products. Of the medicines used $23.4 \%$ were not prescribed by a doctor (self-medication). For men this percentage was $25.7 \%$ and for women $21.9 \%$ $\left(\chi_{1}^{2}=28.50, p<0.0001\right)$. The groups of drugs in which self medication was greater were: antiobesity, laxatives, analgesics/antipyretics, and respiratory products (Table 2 ).

One out of four children polled, had used respiratory products (Table 3 ). There were differences between sexes only in the respiratory products, which were more frequently used by boys $(4.9 \%)$ than girls $(4.2 \%)$. Among children $20.6 \%$ of the medicines used were not prescribed by a doctor (self-medication), $20.1 \%$ for boys and $21.1 \%$ for girls $\left(\chi_{1}^{2}=0.38, p>0.05\right)$. The groups of medicines in which self-medication was 


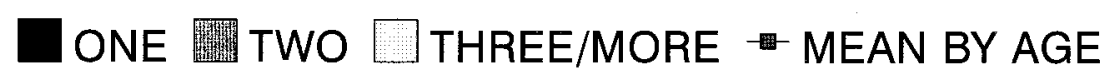

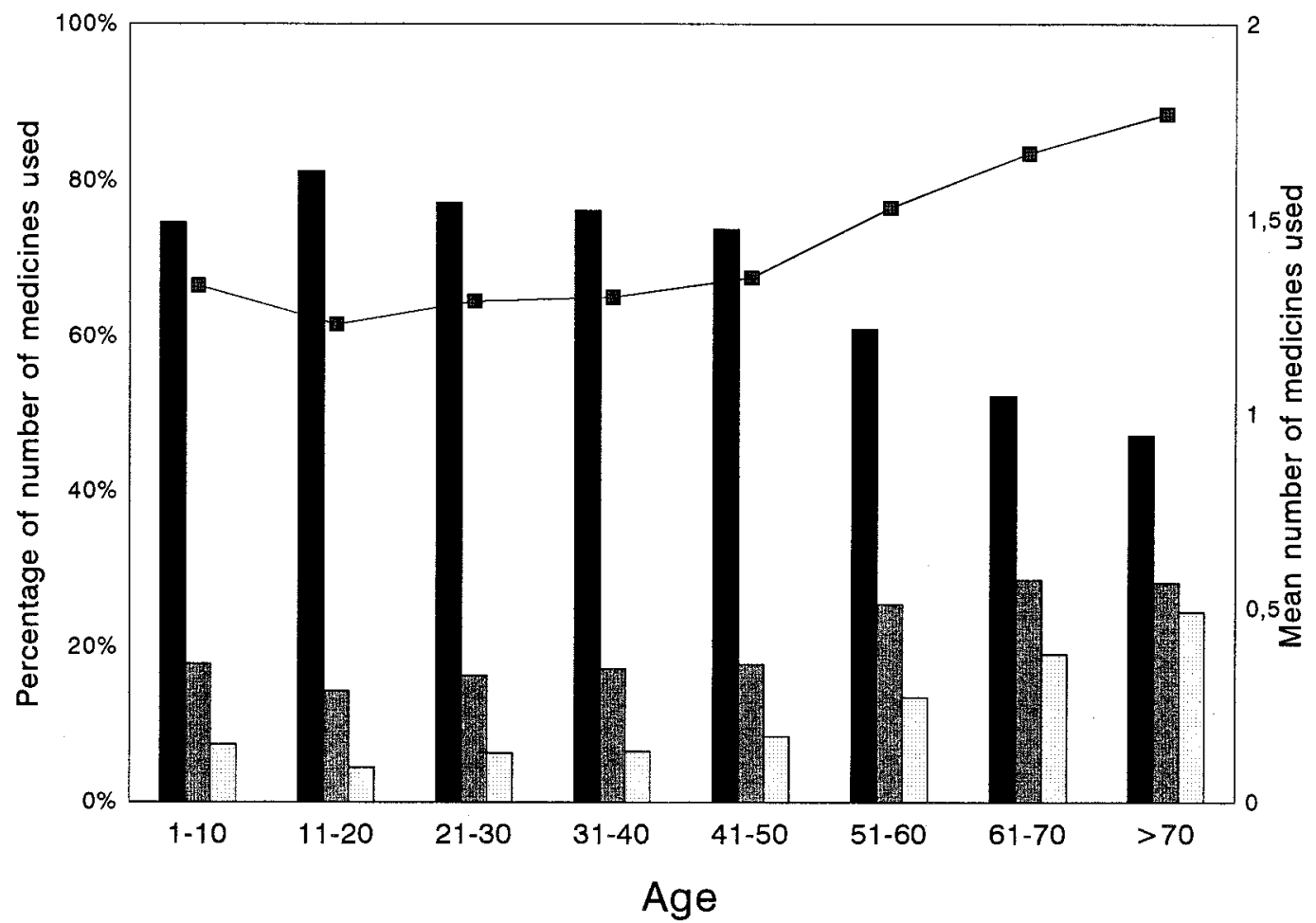

Fig. 2 - Number of medications consumed by the population

more frequent were the analgesics, antipyretics, laxatives, tranquillizers and hypnotics.

\section{DISCUSSION}

The results obtained show the frequency of the use of medicines among the population. About $45 \%$ of those surveyed had used some kind of medicine during the previous 2 weeks.

One of the most important factors influencing the level of drug use is age. Data ${ }^{10,11}$ consistently indicate that the elderly use more drugs than younger age groups. Starting from the 11-20 age group, a progressive increase in frequency and number of medicines used is observed, because morbidity increases with age.
Another influencing factor, although less important than age, is sex. Women not only use medicines more frequently than men, but also take more of them. Visits to the doctor are also more common among women than men. Similar data are found in other studies. ${ }^{10,12}$

Other demographic factors which influence the use of medicines are: marital status, educational background, work situation and size of the community of which one is a member. The widowed and retired use medicines more frequently, which is probably due to their greater age and morbidity. Those people with no schooling or with only primary education use a greater amount of medicines. When considering population size, a clear increase in the frequency of medicine use is observed when the size of the community is bigger. 
Table 1 -Drug use by adults: sociodemographic characteristics

\begin{tabular}{|c|c|c|c|}
\hline & $\begin{array}{l}\text { Total } \\
(\%)\end{array}$ & $\begin{array}{c}\text { Male } \\
(\%)\end{array}$ & $\begin{array}{c}\text { Female } \\
(\%)\end{array}$ \\
\hline \multicolumn{4}{|l|}{ Population size* } \\
\hline$<2000$ & 40.8 & 34.0 & 47.2 \\
\hline $2001-10,000$ & 43.5 & 35.5 & 50.9 \\
\hline $10,001-50,000$ & 45.9 & 40.0 & 51.7 \\
\hline $50,001-100,000$ & 46.5 & 39.9 & 52.8 \\
\hline $100,001-400,000$ & 46.8 & 40.3 & 52.9 \\
\hline $400,001-1,000,000$ & 53.1 & 47.4 & 58.5 \\
\hline$>1,000,000$ & 55.9 & 50.4 & 60.8 \\
\hline \multicolumn{4}{|l|}{ Marital status* } \\
\hline Single & 35.4 & 30.6 & 41.7 \\
\hline Married & 49.5 & 45.2 & 53.6 \\
\hline Divorcee & 48.6 & 44.8 & 50.8 \\
\hline Widowed & 74.1 & 62.2 & 76.6 \\
\hline \multicolumn{4}{|l|}{ Educational status* } \\
\hline No schooling & 66.8 & 56.5 & 72.9 \\
\hline Primary & 45.9 & 39.5 & 51.5 \\
\hline Secundary & 37.3 & 33.3 & 42.2 \\
\hline High & 41.4 & 39.4 & 43.8 \\
\hline University & 42.9 & 41.8 & 44.3 \\
\hline \multicolumn{4}{|l|}{ Occupational status* } \\
\hline Work & 36.8 & 33.6 & 43.8 \\
\hline Retired & 72.5 & 68.9 & 77.6 \\
\hline Unemployed & 39.3 & 33.7 & 46.4 \\
\hline Student & 34.0 & 30.3 & 37.8 \\
\hline Housewife & 55.4 & 38.0 & 55.5 \\
\hline
\end{tabular}

The impact of socio-economic status on the taking of drugs is also evident. ${ }^{11}$

Other studies ${ }^{10}$ have shown that the accessibility of health services, reimbursement systems, etc., may also play a part in the level of drug use. The availability of a doctor is essential in obtaining a prescription, and most consultations lead to a prescription.

As regards the therapeutic groups used, our data should be accepted with caution, mainly because: (i) during the period of the survey (February), the use of certain medicines was more frequent, and (ii) those surveyed were asked only about certain classes of drugs used, in some cases about very specific therapeutic groups (e.g. laxatives) and in others about a wide range of drugs (e.g. medication for the alimentary tract). This is due to the fact that, in order to make it easy for the user to understand, colloquial language has been used, and questions have been asked regarding therapeutic categories which can be identified easily.
Undoubtedly, information obtained from other sources, such as wholesale data, may be more accurate. Figures from wholesale data for 1991 show that the most frequently prescribed drugs were: central nervous system drugs $(17.8 \%)$, respiratory products $(16.8 \%)$, alimentary tract $(16.4 \%)$, and cardiac therapy $(9.7 \%)$. In addition, there are differences in the prescription of certain medicines between countries (e.g. benzodiazepines). ${ }^{13}$

According to our data, one out of five medicines used in the previous 2 weeks, both among adults and children, was not prescribed by a doctor. One of the groups of drugs in which self-medication is greatest is that of analgesics and antipyretics. These data accord with those obtained in other studies. ${ }^{14}$

Two completely different situations are involved in self-medication. Firstly, the use of medicines which, the Spanish legislation stipulates, should be medically prescribed, but which those surveyed obtained without medical prescription: this is the case of tranquillizers and hypnotics, antidepressants, contraceptives, hypotensives, etc. This type of self-medication is frequent among the Spaniards as far as our study is concerned, and shows that in our society the regulations dealing with the dispensing of medication are not strictly adhered to. In addition, there exists the use of over-the-counter preparations, such as certain laxatives, vitamins, analgesics and antipyretics, etc. Logically, these two types of self-medication have completely different consequences from the health point of view.

The increasing over-the-counter drugs and the implication for patients, general practitioners and pharmacists, have been greatly discussed in the last few years, ${ }^{15}$ and emphasis has been placed on the need to promote adequate and proper use of these preparations.

This study is subject to certain limitations when it comes to characterizing patterns concerning medication use. Apart from the above-mentioned therapeutic groups selected, there is no information available with regard to the type of substance used, nor the reason for its prescription. Furthermore, there is no knowledge of how long the substance was used for, nor the doses administered. Certain of these limitations are common to other studies in the general population. ${ }^{16}$

In addition, comparison with figures from other countries is difficult, since in the National Health Surveys, there is either no inclusion of questions 
Table 2 - Class of medication used by the Spanish adult population

\begin{tabular}{lcccc}
\hline Medication & $\begin{array}{c}\text { Total } \\
\%\end{array}$ & $\begin{array}{c}\text { Male } \\
\%\end{array}$ & $\begin{array}{c}\text { Female } \\
\%\end{array}$ & $\begin{array}{c}\text { Self-medication } \\
\%\end{array}$ \\
\hline Antirheumatics* & 4.8 & 2.9 & 6.6 & 6.8 \\
Respiratory products & 14.9 & 14.8 & 15.0 & 35.2 \\
Analgesics and antipyretics* & 10.8 & 8.1 & 13.3 & 45.2 \\
Vitamins* & 2.9 & 2.2 & 3.5 & 27.3 \\
Cardiac therapy & 3.3 & 3.4 & 3.2 & 5.4 \\
Hypotensives* & 7.8 & 5.5 & 10.0 & 6.7 \\
Laxatives* & 1.4 & 0.6 & 2.0 & 50.0 \\
Alimentary tract* & 3.3 & 3.7 & 2.9 & 16.3 \\
Tranquillizers and hypnotics* & 4.2 & 2.7 & 5.6 & 15.6 \\
Antidepressants* & 1.5 & 0.9 & 2.0 & 17.7 \\
Antibiotics* & 2.0 & 1.7 & 2.3 & 21.0 \\
Contraceptives* & 1.2 & 0.0 & 2.3 & 51.4 \\
Antiobesity* & 0.3 & 0.1 & 0.5 & 12.7 \\
Antiallergic products & 1.3 & 1.2 & 1.4 & 13.2 \\
Cholesterol reducers* & 2.6 & 2.1 & 3.1 & 11.8 \\
Antidiabetic therapy* & 2.3 & 1.7 & 2.8 & 13.9 \\
Various* & 6.0 & 5.0 & 6.8 & \\
$n$ & 21084 & 10176 & 10877 & \\
\hline
\end{tabular}

$* p<0.005\left(\chi^{2}\right)$.

Figures for self-medication (non-medical prescription) refer to each class of medication.

Please note some patients use more than one class of medication and hence the individual classes cannot be added up to reach the total.

Table 3 - Class of medication used by Spanish children

\begin{tabular}{lrrrc}
\hline Medication & $\begin{array}{c}\text { Total } \\
\%\end{array}$ & $\begin{array}{c}\text { Male } \\
\%\end{array}$ & $\begin{array}{c}\text { Female } \\
\%\end{array}$ & $\begin{array}{c}\text { Self-medication } \\
\%\end{array}$ \\
\hline Respiratory products* & 24.4 & 22.8 & 26.3 & 15.1 \\
Analgesics & 5.6 & 5.6 & 5.6 & 48.2 \\
Antipyretics & 4.6 & 4.9 & 4.2 & 18.0 \\
Vitamins & 3.1 & 2.7 & 3.5 & 28.4 \\
Antiemetics & 0.6 & 0.6 & 0.5 & 20.5 \\
Antidiarrhoeals & 0.8 & 0.6 & 1.0 & 40.0 \\
Laxatives & 0.1 & 0.1 & 0.1 & 29.9 \\
Tranquillizers and hypnotics & 0.4 & 0.4 & 0.4 & 15.7 \\
Antibiotics & 4.5 & 4.0 & 4.9 & 14.9 \\
Antiallergic products & 1.9 & 2.2 & 1.7 & 17.0 \\
Various & 2.7 & 2.9 & 2.6 & \\
$n$ & 5250 & 2686 & 2539 & \\
\hline
\end{tabular}

$* p<0.005\left(\chi^{2}\right)$.

Figures for self-medication (non-medical prescription) refer to each class of medication.

Please note some patients use more than one class of medication and hence the individual classes cannot be added up to reach the total.

regarding medication, or these refer to specific therapeutic groups. For example, in Canada's Health Promotion Survey, ${ }^{17}$ those surveyed were asked if in the past 12 months they had used (i) sleeping pills (ii) pep pills, stimulants, or (iii) tranquilizers such as valium; in the 1993 Swiss
Health Survey, ${ }^{18}$ questions were asked about the use of sleeping pills and tranquilizers in the 7 days preceding the interview. However, in the Health Survey for England, ${ }^{19}$ (a series of annual surveys designed to monitor trends in the nation's health), as part of the nurse-visit, information was collected 
about any prescribed medication the respondent was taking at the time (last 7 days). The nurses recorded details of all medicines being taken from the medicine containers. The trends observed were similar to those found by us. About $38 \%$ of adults (over 16) were taking at least one prescribed medicine, and their use was related to sex and age, as well as to reported general health and reported long-standing illness or disabilities. Although there are methodological guidelines for surveys on health, ${ }^{20,21}$ these are lacking in the field of medication use by the population.

Provided these limitations are recognized, it can be accepted that attempts, such as this to carry out a survey on medication use levels among the population offer important information which complements other drug utilization studies; for instance, sales and prescriptions. To give examples, such studies enable us to understand the everinceasing use of drugs, the sociodemograpic factors which relate to their use, the joint use of drugs and alcohol, ${ }^{22}$ the magnitude of self-medication, etc.

The freqent use of medicines has led to the need to devise strategies encouraging rational use. It is, therefore, necessary to have reliable information, not only concerning pharmaceutical needs in the community and their cost, but also regarding the use of medicines. In fact, there are few studies at general population level, like the one presented here, which offer important useful information on the use of medicines by the public.

\section{ACKNOWLEDGEMENTS}

We thank the Ministerio de Sanidad y Consumo (Subdireccion General de Informacion Sanitaria y Estadísticas Sanitarias) for providing us with the 1993 National Household Health Survey computerized database.

\section{REFERENCES}

1. WHO Expert Committee. The Selection of Essential Drugs, Technical Report Series No 615. World Health Organization, Geneva, 1977.

2. Lee, D. and Bergman, U. Studies of drug utilization. In: Pharmacoepidemiology, 2nd edn. Storm, B. L. (Ed.). John Wiley \& Sons, Chichester, 1994, pp. 379393.

3. Capellà, D. Descriptive tools and analysis. In: Drug Utilization studies: Methods and Uses. Dukes, M. N. G. (Ed.). WHO Regional Publications, European Series No. 45, Copenhagen, 1993, pp. 55-78.
4. Bergman, U., Grimsson, A., Wahba, A. H. W. and Westerholm, B. (Eds). Studies in Drug Utilization. Methods and Applications. World Health Organization, Regional Office for Europe, Copenhagen, 1979.

5. Haaijer-Ruskamp, F. M. and Hemminki, E. The social aspects of drug use. In: Drug Utilization Studies: Methods and Uses. Dukes, M. N. G. (Ed.). WHO Regional Publications, European Series No. 45, Copenhagen, 1993, pp. 97-124.

6. Garcia, F., Scott, A. I., Stika, L. and Westerholm, B. Health authorities and drug utilization studies. In: Drug Utilization Studies: Methods and Uses. Dukes, M. N. G. (Ed.). WHO Regional Publications, European Series No. 45, Copenhagen, 1993, pp. 147-167.

7. Laporte, J. R., Porta, M. and Capellà, D. Drug utilization studies: a tool for determining the effectiveness of drug use. British Journal of Clinical Pharmacology 1983; 16: 301-304.

8. Sanchez-Eznarriaga, C. and Guerra, F. J. Evolución de la prestación farmacéutica en el Sistema Nacional de Salud (período 1984-1994). (Evolution of free pharmaceutical provision in the national health service (1984 to 1994 period)). Atencion Primaria 1995; 16: 546-550.

9. Ministerio de Sanidad y Consumo. Encuesta Nacional de Salud de España 1993. Ministerio de Sanidad y Consumo, Madrid, 1995.

10. Nordic Statistics on Medicines 1990-1992. NLN Publication No 34. Nordiska Läkemedelsnämnden. Nordic Council on Medicines, Uppsala, 1993.

11. Leufkens, H. G. and Urquhart, J. Variability in patterns of drug usage. Journal of Pharmacy and Pharmacology 1994; 46 (Suppl. 1): 433-437.

12. Baum, C., Kennedy, D. L., Forbes, M. B. and Jones, J. K. Drug use in the United States in 1981. Journal of the American Medical Association 1984; 251: 1293-1297.

13. Woods, J. H., Katz, J. L. and Winger, G. Benzodiazepines: use, abuse, and consequences. Pharmacological Reviews 1992; 44: 151-347.

14. Kogan, M. D., Pappas, G., Yu, S. M. and Kotelchuck, M. Over-the-counter medication use among US preschool-age children. Journal of the American Medical Association 1994; 272: 1025-1030.

15. Editorial. Over-the-counter drugs. Lancet 1994; 343: 1374-1375.

16. Olfson, M. and Pincus, H. A. Use of benzodiazepines in the community. Archives of Internal Medicine 1994; 154: 1235-1240.

17. Health and Welfare Canada. Canada's Health Promotion Survey, Technical Report. Ministry of Supply and Services Canada. Ottawa, 1988.

18. Swiss Federal Statistical Office. Swiss Health Survey. Swiss Federal Statistical Office, Berne, 1994.

19. Office of Population Censuses \& Surveys. Health Survey for England 1992. Office of Population Censuses \& Surveys, Social Survey Division, HMSO, London, 1994. 
20. United Nations. Guidelines for Household Surveys on Health. United Nations Department for Economic and Social Information and Policy Analysis, Statistical Division, New York, 1995.

21. Third Consultation to Develop Common Methods and Instruments for Health Interview Surveys. Report on a WHO Meeting. World Health Organ- ization, Regional Office for Europe, and the Netherlands Central Bureau of Statistics, Voorburg, 1993 (EUR/ICP/HST 124).

22. Del Rio, M. C., Prada, C. and Alvarez, F. J. The use of medication and alcohol among the Spanish population. British Journal of Clinical Pharmacology 1996; 41: 253-255. 